\title{
The effect of exercise training and water extract from propolis intake on the antioxidant enzymes activity of skeletal muscle and liver in rat
}

\author{
Tae Dong Kwon ${ }^{1}$, Mong Woo $\mathrm{Lee}^{2}$ and Ki Hoon Kim* \\ ${ }^{1}$ Department of Leisure Sports, Kyungpook National University, Sangju, Korea \\ ${ }^{2}$ Department of Physical Education, Kyungnam University, Changwon, Korea
}

(Received: 2014/01/16, Revised: 2014/02/07, Published online: 2014/02/11)

[Purpose] In this study, the authors have intended to investigate the effects that the exercise training and the intake of the water extract from propolis have on the activity of antioxidant enzymes. [Methods] For this purpose, the exercise training (70\% $\mathrm{VO}_{2}$ max treadmill running exercise for $\left.60 \mathrm{~min}\right)$ of 5 times per week for six weeks and the intake $(50 \mathrm{mg} / \mathrm{kg} / \mathrm{day})$ of the water extract from propolis were performed by separating the experimental animals (SD rats, $n=32)$ into $\mathrm{CON}(\mathrm{n}=8)$ group, $\mathrm{CON}+\mathrm{Ex}(\mathrm{n}=8)$, $\mathrm{PA}(\mathrm{n}=8)$, and $\mathrm{PA}+\operatorname{Ex}(\mathrm{n}=8)$. [Results] As a result, the following conclusions were obtained: The concentration of the blood glucose and insulin of the CON+Ex group and PA+Ex group which are the exercise parallel group were significantly decreased in comparison with the control group, whereas if comparing the glycogen concentration in skeletal muscle and liver tissue between the exercise parallel group and the CON group, the former showed significantly high value in comparison with the latter $(p<.05)$. In the case of the activity of the antioxidant enzyme in the skeletal muscle and the liver tissue, the activities of SOD, GPX and CAT in the gastrocnemius muscle tissue of the experimental animals showed significantly high value in PA+Ex group in comparison with other experimental groups $(p<.05)$. In addition, the SOD activity in the liver tissue showed that only PA+Ex group was significantly increased, whereas GDX activity showed significantly higher value in CON+Ex group and PA group than CON group $(p<.05)$. However, the activity of CAT in the liver tissue showed that there is no difference between the experimental groups. As a result that measured the concentration of MDA in order to evaluate the damage level of the tissue by oxygen free radicals, the difference between the groups in the liver tissue was not shown, while it was shown that only PA+Ex group in the skeletal muscle tissue was significantly decreased in comparison with other experimental groups $(p<.05)$. [Conclusion] Taken together the above findings, it is considered that the parallel treatment of the exercise training and the water extract from propolis can not only increase the use of glycogen of the skeletal muscle and liver tissue, but also it can give the effect to suppress the creation of active oxygen by inducing the activity of the antioxidant enzyme in the body, and in the future, the possibility as the exercise supplements and the antioxidant of the water-soluble propolis are expected. [Keyword] Exercise, propolis, antioxidant enzyme.

\section{INTRODUCTION}

Because the oxygen consumption and the electron transport required to generate the energy in the pathological situation such as acute exercise and chronic disease are greatly increased in comparison with the rest condition, some of the cells related to them are bound to be exposed to the metabolic stress [1,2]. The tissues such as the liver or the skeletal muscle that play a central role of energy metabolism in this process generate the free radicals that are very unstable and have the high reactivity due to the byproduct according to the oxidation process $[3,4]$. It has been known that the free radicals generated in the tissues like this reduce the fluidity of the cell membrane by causing the damage of lipid peroxidation or protein oxidation, and oxidative DNA, and they cause the serious function damage by increasing the membrane permeability [5].

In the free radicals generated in the unstable oxidation process, there are various reactive oxygen species (ROS) and peroxides such as superoxide anion $\left(\mathrm{O}_{2}{ }^{-}\right)$, hydrogen peroxide radical $(\cdot \mathrm{OOH})$, and hydroxyl radical $(\cdot \mathrm{OH})$, but fortunately the various antioxidant defense systems to quickly remove

\footnotetext{
* Corresponding author: Ki-Hoon Kim, Tel. 82-10-3035-7814, Email. b612kihoon@nate.com

(c)2014 The Korean Society for Exercise Nutrition
} 
them have been well built in the human body. In other words, various auxiliary substances containing the non-enzymatic chemicals such as superoxide dismutase (SOD), glutathione peroxidase (GPX), catalase (CAT), vitamine $\mathrm{C}$ and $\mathrm{E}$, betacarotene, and glutathione known as the antioxidant enzyme materals exist in the body [6,7]. However, because it can not completely cope with the peroxidative reaction of continuous cells with only these antioxidants in the body, the researchers are having an interest in the development of various new materials which can supplement them.

Viewing recent trends in the related research, the studies on human body -friendly natural products have been mainly researched because the abuse and side effect for the chemical should be considered. Because the propolis among them contain the physiological control components of about 150 species including polyphenols (flavonoids, phenolic acid conjugate), terepenes, octacosanol, etc., it has been received attention as a multi-functional natural substance for the effects of physiological control such as antibiotics, anti-inflammatory drug, anti-microbial and anti-cancer effects, etc. [8-10].

It has been known that the propolis can effectively block various pathogenic bacteria such as mostly bacteria or viruses invading from the outside of honeycomb as the material which honeybees have made by mixing their own saliva, enzyme, water and beeswax with the vegetable saps and resins collected from trees, grasses and flowers [8]. However, it will not be able to be excluded that the ingredient of medicinal herbs and efficacy may be a little difference according to various local characteristics and collection method or the extraction form in the way that the propolis is a natural substance obtained from the natural state. In fact, the extraction method of the propolis that are making the main part until recently uses the ethanol, and because the extract (EEP) itself contains the alcohol of high concentration as well as the pollen or oil and fat component inducing the allergic reactions, the controversy for the stability of the hyperthermia or the heart rate acceleration in the body, even the hepatocellular damage has been continued [11-13]. In addition, the studies on the components of the propolis which is produced from the domestic native honeybees despite of that various bioactive effects of propolis has been suggested are still insufficient, and particularly, in the case of the water extracts from propolis, the studies that investigate the effect of the biological activity of propolis in the kinematic aspect have been conducted very limitedly in the clinical $[4,14]$.

Therefore, in this study, the authors have intended to investigate that the intake of the water extract from propolis produced from the domestic native honey has what effect on the activity of antioxidant enzyme in the liver and the skeletal muscle after training of exercise using the experimental animals. It is considered that this will be able to provide the data needed to develop various antioxidant related to the exercise adaptation as well as the verification of the efficacy of propolis made in Korea.

\section{RESEARCH METHOD}

\section{Experimental Objective and Group Classification}

The experimental animals used in this study were applied to the experimental environment for 6 weeks by classifying into the control group $(\mathrm{CON})$ and the control exercise group $(\mathrm{CON}+\mathrm{Ex})$, the propolis administration group $(\mathrm{PA})$ and the propolis intake and exercise group (PA + Ex) targeting ( $\mathrm{n}=$ 32) the Sprague-Dawley species of about 6-weeks-old. The intake capacity of propolis was determined based on the previous studies that if the intake capacity of the ethanol extract from propolis was $50 \mathrm{mg} / \mathrm{kg}$, the oxidative stress in the liver tissue was lowest $[15,16]$.

\section{EXPERIMENTAL METHOD}

\section{Manufacture of Water Extract from Propolis}

The samples used in this study were prepared by dissolving the powder in DW at the ratio of 1:1,000 of the powder versus water through the pulverization process in the solid state after storing at $4^{\circ} \mathrm{C}$ for 24 hours of the propolis original lumps provided by A honey company in Korea. The dissolved liquid was extracted by stirring at $60 \mathrm{rpm}$ for 18 hours at $70-95^{\circ} \mathrm{C}$ using a shaking water bath. After this, the extract was separated into the supernatant and the precipitate through centrifugation, and the separated solution was filtered using $0.2 \mu \mathrm{m}$ whatman filter, and then the filtrate was concentrated by a rotary evaporator(EYELA, Tokyo, Japan) and manufactured to pure water extract from propolis. When the water extract was administered to the experimental animals, the dose needed was dissolved in DW and was orally administered by 5 times per week by using a feeding needle by $2 \mathrm{ml}$ in one time a day. The same condition giving the DW of same amount was given to the control groups.

\section{Exercise Loading Method}

For the exercise loading applied for 6 weeks, the exercise loading for 60 minutes per day was applied over 5 times per 
week using the treadmill for the experimental animals, and for the exercise intensity applied, the initial 10 minutes were loaded at the speed of $16 \mathrm{~m} / \mathrm{min}$ and then the next 10 minutes, at the speed of $22 \mathrm{~m} / \mathrm{min}$, and the remainder 40 minutes, at the speed of $25 \mathrm{~m} / \mathrm{min}$, and consequently, the running of total 60 minutes was conducted. It has been known that in the case of the SD rat, the exercise intensity of $25 \mathrm{~m} / \mathrm{min}$ is corresponded about $70 \%$ of the maximal oxygen uptake [7].

\section{Sampling}

The experimental animals for experiments were fasted for one night after last exercise of 40 hours, and then the experiments were started at next $10 \mathrm{am}$, and they were anesthetized by injecting the pentothal sodium (Daihan Pharm Co., Korea) of $40 \mathrm{mg} / \mathrm{kg}$ into the abdominal, and then have taken blood through the abdominal aorta and were sacrificed. The experimental animal's blood was taken immediately after being sacrificed, and the plasma was obtained immediately by centrifuging, and was kept in a freezer at $-80^{\circ} \mathrm{C}$ until to analyze the plasma. In addition, in order to measure the glycogen concentration, the antioxidation enzyme activity and MDA concentration in the liver and skeletal muscle tissue, the gastroncnemius muscle of the right leg of the experimental animal was separately removed and weighed, and then analyzed.

\section{Analytical method}

The kit (Sigma Chemical Co, MO, USA) using the enzymatic method was used for the analysis of blood glucose, and the concentration of insulin was measured using the kit for ELISA analysis (Mercodia AB, Uppsala, Sweden).

The removed tissue was made to fragments, and the grinding homogenate $(20 \% \mathrm{~W} / \mathrm{V})$ was made by a glass teflon homogenizer (Virtis, USA) by adding $0.25 \mathrm{M}$ sucrose solution of 4 times volume in them after weighing the certain amount among the fragments, and the homogenate was used as a sample for MDA content measurement. In addition, the supernatant obtained by secondary centrifugation again the first supernatant after centrifuging the homogenate $(600 \times \mathrm{g}$ for $10 \mathrm{~min}$ ) was used as the sample of SOD and GPX activity measurement, and the pellet was suspended in $0.25 \mathrm{M}$ sucrose solution, and then was used as the sample for CAT activity measurement after freezing and thawing the suspension. For SOD activity measurement, the enzyme activity was calculated measuring at $560 \mathrm{~nm}$ the absorbance of the hematein generated by being reacted at $25^{\circ} \mathrm{C}$ by adding $10 \mu \mathrm{M}$ hematoxylin and the enzyme solution in $50 \mathrm{Mm}$ phosphate buffer solution $(\mathrm{pH}$
7.5) which $0.1 \mathrm{mM}$ EDTA was contained according to the method [18] that observed the degree of inhibition of the hematoxylin and auto-oxidation. The unit of activity was proposed so that the degree inhibiting $50 \%$ of the autooxidation of hematoxylin of the liquid which is reacted without putting the enzyme liquid is indicated as 1 unit. For the activity measurement of GPX, glutathione substrate and the coenzyme NADPH were reacted with a sample at $25^{\circ} \mathrm{C}$ for 5 minutes, and the absorbance variation of the reactant was measured at $340 \mathrm{~nm}$, and for the unit of activity, the amount of NADPH oxidized for 1 minute from the protein of $1 \mathrm{mg}$ contained in the sample was indicated as nmole. For CAT activity measurement, the degree of the reduction of $\mathrm{H}_{2} \mathrm{O}_{2}$ which was used as the substrate was indicated by measuring the absorbance at $240 \mathrm{~nm}$, and the activity was calculated in $\mu \mathrm{mol}$ unit by using the molecular absorption coefficient $\left(0.041 \mathrm{mM}^{-1} \cdot \mathrm{cm}^{-1}\right)$, and for MDA activity measurement, the pyrognostics of the lipoperoxide in the sample with thiobarbituric acid were performed under acidic conditions, and the resulting material was indicated as nmol per $\mathrm{g}$ tissue after measuring the absorbance at $532 \mathrm{~nm}$. The protein quantification was measured using the bovine serum albumin [19], and the glycogen concentration was quantified by the method that uses the anthrone reaction [20]. In short, the removed tissue was cut into the fragments, and the fragments were heated in $30 \% \mathrm{KOH}$ solution of $5 \mathrm{ml}$ saturated with $\mathrm{Na}_{2} \mathrm{SO}_{4}$ for 25 minutes, and then they were incubated at $4{ }^{\circ} \mathrm{C}$ for 30 minutes by putting $95 \%$ ethylalcohol of $1 \mathrm{ml}$, and the incubated fragments were centrifuged at 2,000 rpm and the remaining pellet of $5 \mathrm{ml}$ was homogenized by DW, and $1 \mathrm{ml}$ of this solution was dissolved in sulfuric acid and then was quantified by the colorimetry at $490 \mathrm{~nm}$.

\section{Data analysis}

In the statistical processing for the experimental results of data processing, the average and the standard deviation by each variable were calculated using SPSS/PC + . To verify the significance between each group, one-way ANOVA was performed, and Tukey method was used as the post-hoc comparison for the significant difference. At this time, all the results were verified the significance at $\mathrm{p}<0.05$ level.

\section{RESULTS}

In this study, the effect of the exercise loading and the intake of water extract from propolis on the antioxidant enzyme activity of the skeletal muscle and liver tissue were 
observed, and the blood glucose, insulin and glycogen concentration in each experimental group were measured for the quantitative evaluation for the exercise. As a result, the following results were obtained:

\section{Changes of glucose and insulin concentration in blood}

Among the changes of the glucose and insulin concentration in blood of the experimental animals, in the case of the blood glucose, the control exercise group $(\mathrm{CON}+\mathrm{Ex})$ and the propolis administration and exercise parallel group (PA + Ex) showed the statistical difference by being reduced about $15 \%$ and $16 \%$, respectively in comparison with the control group $(\mathrm{CON})(p<.05)$, and also in the case of the insulin in blood, $\mathrm{CON}+\mathrm{Ex}$ group and PA + Ex group showed significantly lower values by being reduced about $24 \%$ and $23 \%$ in comparison with CON group $(p<.05)$. On the other hand, the propolis administration group (PA) alone was slightly reduced compared to CON group without the statistical difference but showed significantly higher numerical value for only $\mathrm{CON}+\operatorname{Ex}$ group $(p<.05)$.

Table 1. Comparisons of blood glucose and insulin concentration.

\begin{tabular}{lcc}
\hline & Glucose $(\mathrm{mg} / \mathrm{dl})$ & insulin $(\mu \mathrm{u} / \mathrm{ml})$ \\
\hline CON & $107.3 \pm 8.66$ & $25.2 \pm 2.91$ \\
CON + Ex & $91.7 \pm 8.61^{\mathrm{a}}$ & $19.1 \pm 3.54^{\mathrm{a}}$ \\
$\mathrm{PA}$ & $101.1 \pm 8.52$ & $23.1 \pm 2.11^{\mathrm{b}}$ \\
$\mathrm{PA}+\mathrm{Ex}$ & $89.8 \pm 8.68^{\mathrm{a}}$ & $19.4 \pm 2.93^{\mathrm{a}}$ \\
$F$ & 7.305 & 8.196 \\
$\mathrm{p}$ & .001 & .001 \\
\hline
\end{tabular}

CON: control group; $\mathrm{CON}+\mathrm{Ex}$ : $\mathrm{CON}$ and exercise group; PA: propolis administration group; PA + Ex: PA and exercise group Values are Mean $\pm \mathrm{SD}$.

${ }^{\mathrm{a}} p<.05$ vs $\mathrm{CON},{ }^{\mathrm{b}} p<.05$ vs $\mathrm{CON}+\mathrm{Ex}$

Changes of glycogen concentration in skeletal muscle and liver

Table 2. The glycogen concentration of muscle and liver.

\begin{tabular}{lcc}
\hline & \multicolumn{2}{c}{ Glycogen concentration, mg/100g wet. wt. } \\
\cline { 2 - 3 } & Muscle & Liver \\
\hline CON & $2.2 \pm 0.36$ & $19.2 \pm 2.77$ \\
CON + Ex & $3.2 \pm 0.33^{\mathrm{a}}$ & $27.8 \pm 2.38^{\mathrm{a}}$ \\
$\mathrm{PA}$ & $2.4 \pm 0.46^{\mathrm{b}}$ & $18.7 \pm 4.54^{\mathrm{b}}$ \\
$\mathrm{PA}+\mathrm{Ex}$ & $3.0 \pm 0.25^{\mathrm{a}, \mathrm{c}}$ & $28.9 \pm 2.77^{\mathrm{a}, \mathrm{c}}$ \\
$F$ & 13.204 & 20.771 \\
$\mathrm{p}$ & .001 & .001 \\
\hline
\end{tabular}

Values are Mean $\pm \mathrm{SD}$.

${ }_{p}^{\mathrm{a}}<.05$ vs $\mathrm{CON},{ }^{\mathrm{b}} p<.05$ vs $\mathrm{CON}+\mathrm{Ex},{ }^{\mathrm{c}} p<.05$ vs $\mathrm{PA}$
In this study, the authors have measured the glycogen concentration in the skeletal muscle and liver tissue for the quantitative evaluation in these tissue for the exercise load applied to the experimental animals. As a result, comparing the change of glycogen concentration in the skeletal muscle and liver tissue, $\mathrm{CON}+\mathrm{Ex}$ group and PA + Ex group which are the exercise parallel groups showed significantly higher value in comparison with $\mathrm{CON}$ and $\mathrm{PA}$ which did not run parallel with the exercise $(p<.05)$, and there was no difference between the exercise parallel groups.

\section{Changes of antioxidant enzyme in skeletal muscle and liver}

As a result to analyze the antioxidant enzyme in the skeletal muscle and liver tissue according to the exercise loading and the intake of propolis, in the case of the activity of SOD (unit/mg protein) in both tissues, PA + Ex group was significantly increased in comparison with the remainder group $(p<.05)$, and in the case of GPX activity $(\mathrm{nmol} / \mathrm{min} / \mathrm{mg}$ protein) in the skeletal muscle tissue, also PA + Ex group was significantly increased in comparison with the remainder
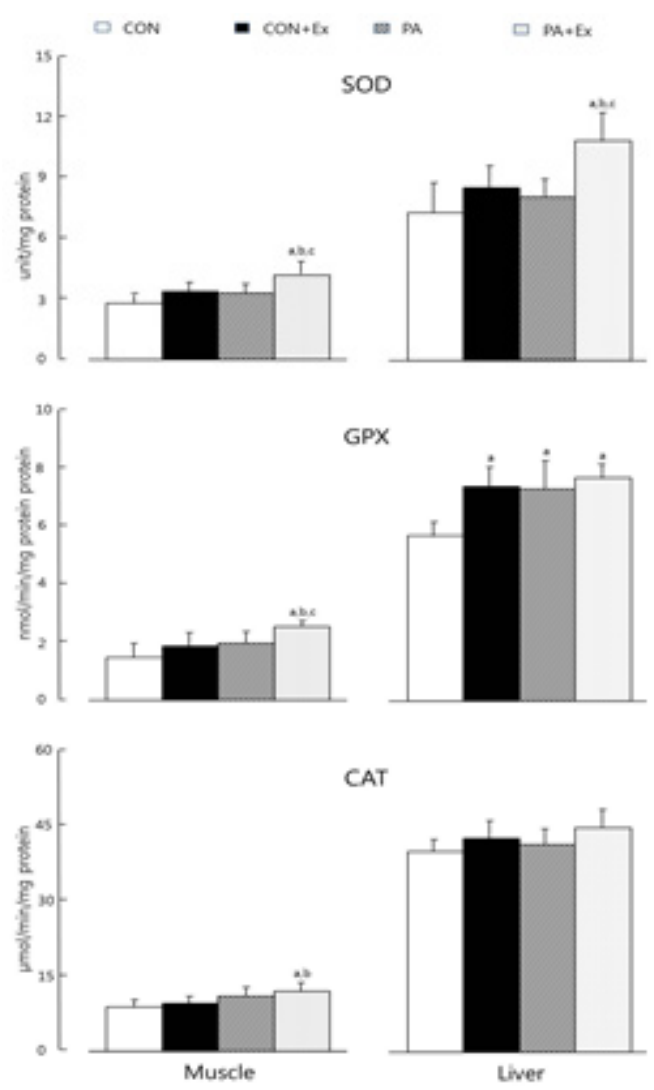

Fig. 1. The activityes of andtioxidant enzymes of muscle and liver in rat. SOD, GPX and CAT mean superoxidase, glutathione peroxidase and catalase. Ex means exercise. Values are Mean \pm SD. ${ }^{a} p<.05$ vs $\operatorname{CON},{ }^{b} p$ $<.05$ vs $\mathrm{CON}+\mathrm{Ex},{ }^{\mathrm{c}} p<.05$ vs $\mathrm{PA}$ 


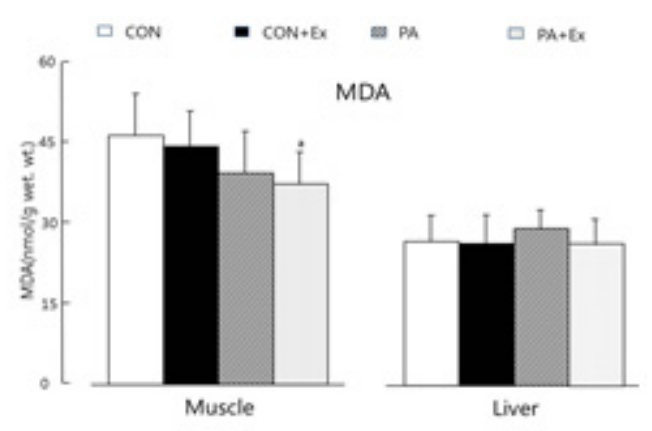

Fig. 2. The concentration of malondialdchyde(MDA) of muscle and liver in rat. Values are Mean $\pm \mathrm{SD}$. ${ }^{\mathrm{a}} p<.05$ vs $\mathrm{CON}$

group, while all the experiment groups $(\mathrm{CON}+\mathrm{Ex}, \mathrm{PA}, \mathrm{PA}$ $+\mathrm{Ex})$ in the liver tissue were significantly increased in comparison with the control $(\mathrm{CON})$ group $(p<.05)$. In addition, in the case of the CAT activity ( $\mu \mathrm{mol} / \mathrm{min} / \mathrm{mg}$ protein), the PA + Ex group was significantly increased in comparison with the $\mathrm{CON}$ group and $\mathrm{CON}+$ Ex group in only the skeletal muscle tissue, and there was no statistical difference between groups in the liver tissue $(p<.05)$.

\section{Changes of MDA concentration in skeletal muscle and liver}

In this study, the concentration $(\mathrm{nmol} / \mathrm{g}$ ) of MDA in the skeletal muscle and liver tissues was measured in order to evaluate the degree of damage in each tissue due to the oxygen free radical. As a result, in only the skeletal muscle, the PA + EX group showed significantly lower value in comparison with the CON group $(p<.05)$, and the difference between groups in the liver was not shown.

\section{DISCUSSION}

The cells generated the minimum oxygen free radicals with strong reactivity in the pathological situation such as acute exercise or disease, and the free radicals thus generated are associated with various pathological condition ranging from the vascular diseases and cancer as well as various metabolic diseases [21-23]. Fortunately, in the human body, various defense mechanisms that are able to cope with such oxygen free radicals exist, and in particular, much attention has been given to the role by the antioxidant enzyme. It is considered that this defense mechanisms result from that the antioxidant enzyme may be not only synthesized in the body, but also can be sufficiently complemented from the outside.

In this study, the authors have intended to investigate the activity of the antioxidant enzymes through the effectiveness verification of the natural antioxidant that can minimize the side effects in the body, and the exercise adaptation, as part of this effort. For this purpose, the intake of the propolis which has been known to have the effects of various physiological activities, and the exercise training were applied to the experimental animals (SD rats) for six weeks. The propolis used in this study is the natural propolis produced in Korea, and the pure water extraction method rather than existing ethanol extraction method was applied as a component extraction method, and consequently the samples were differentiated from other samples.

In this study, first the concentration of glucose and insulin in blood and the concentration of glycogen in the skeletal muscle and liver were analyzed for the quantitative evaluation for the exercise training given to the experimental animals. As a result, the concentration of the glucose and insulin in blood of the CON + Ex group and PA + Ex group which are the exercise parallel group were significantly decreased in comparison with the control group, whereas it was confirmed that in the case of the concentration of glycogen in the skeletal muscle and liver tissue, the exercise parallel groups showed significantly high value in comparison with $\mathrm{CON}$ group. It is considered that this resulted from the enhancement effect of insulin sensitivity of exercise training [24], and consequently the insulin sensitivity is improved and the glycogenosis of the skeletal muscle and liver was induced $[25,26]$. These results are also the indicator to mean that the exercise program applied to the experimental animals in this study was appropriately made in conjunction with the glycogen metabolism. However, the effect of the propolis intake could not be confirmed in this study, unlike in some previous studies that recently have argued the insulin sensitivity improvement [27] and blood glucose dropping effect related to the glucose metabolism [28,29] among the effects of physiological activity of propolis. In addition, it is considered that it should be taken account of the previous studies [32] that there may be the metabolic difference $[30,31]$ according to the form of muscular fiber, or the difference of glycogen use according to fasting and the analysis timing after exercise loading for the fact that the rate of accumulation of glycogen in the tissue was relatively very high in the liver tissue in comparison with the skeletal muscle in this study.

On the other hand, normally a very strong acute exercise or long-term severe endurance exercise accompanies the creation of the oxygen free radicals of small amount (ROS), and it is known that the intracellular activity of antioxidant enzymes is increased due to the operation of the defense mechanism about this $[2,4,7]$. However, because various reactive oxygen species (ROS) generated in the exercise or various pathological situations are too hard to effectively remove by only 
the antioxidant enzyme existed in the body, the cells in the body will be received damage. Therefore, many physiologists have sought the various measures to increase the activity and expression the antioxidant enzyme in the body. Reportedly identified up to date, the regular exercise of appropriate intensity can increase the activity of the antioxidant enzyme in the blood and a part of muscle tissue [33,34], and the expression of these enzymes has been known to be capable of inducing by the intake or administration various nonenzymatic antioxidants [35,36]. In this study, two aspects for the acceleration of the antioxidant system in the body, namely, the access for the exercise training and the intake of nonenzymatic antioxidant were attempted. The non-enzymatic antioxidant proposed in this study is pure water extract from propolis which the effects of various biological activity have been known as a human-friendly natural medicinal product which has few side effects.

As the result of a study on the activity of the antioxidant enzymes in the skeletal muscle and liver tissue, SOD, GPX and CAT activity in the gastrocnemius tissue of the experimental animals showed significantly higher value than other experimental group in the treatment group $(\mathrm{PA}+\mathrm{Ex})$ that simultaneously runs parallel with exercise and propolis. In addition, the SOD activity in the liver tissue showed that only $\mathrm{PA}+\mathrm{Ex}$ group was significantly increased, whereas GDX activity showed significantly higher value in $\mathrm{CON}+\mathrm{Ex}$ group which are the control exercise group and also PA group showed significantly high activity in comparison with the CON group which is a control group $(p<.05)$. However, the activity of CAT in the liver tissue showed that there is no difference between the experimental groups. On the other hand, this aspect showed the similar result in also the results that measure the concentration of MDA well known as the scale $[37,38]$ of lipid peroxidation in order to evaluate the extent of tissue damage by the oxygen free radicals. In other words, the difference between the groups in the liver tissue did not appear, whereas only PA + Ex group in skeletal muscle tissue was significantly decreased in comparison with other experimental groups. These results can be assumed that the activity of antioxidant enzyme and the damage degree of tissue were appeared the synergy effect according to the concurrent application of the exercise training and nonenzymatic antioxidant. The previous studies arguing that the number and size of mitochondria in skeletal muscle through exercise training can be increased [39,40], and the expression leading of the antioxidant enzyme existing in the mitochondria through the increase of intracellular mitochondria biosynthesis and the damage by oxidative stress can be suppressed support the theoretical background of above results [40,41]. Moreover, it is considered that the phenomenon that the activity of antioxidant enzyme and the concentration of MDA in skeletal muscle tissue were significantly decreased than liver tissue was the result that the ability of adapt of the antioxidant enzyme system by the oxidative stress was composed more effectively in skeletal muscle in comparison with other organs $[34,43]$. In addition, in PA + Ex group which is the single propolis intake group in this study, the concentration of GPX in liver tissue was increased to significantly high value, and statistically significant difference was not appear but the antioxidant enzyme activity in skeletal muscle and liver tissue showed general increase aspect. It is considered that since even the concentration of MDA in skeletal muscle showed the tendency to somewhat decrease in comparison with the CON + EX group which is the control and exercise group, it is the result that indirectly demonstrates the antioxidant effect for propolis. This is the results that somewhat coincide with the research contents to reveal that CAPE(caffeic acid phenethyl ester) including water-soluble flavonoids of propolis components have a positive effect to the product inhibition of the lipid peroxidation through hydroxyl radical removal and the inhibition of lipoxy-genase [44-46]. In other words, because the flavonoids such as Artepillin C(3,5-diprenyl4-hydroxyci-namic acid) which propolis is containing and the caffeate ingredients such as benzyl caffeate and cinnamic acid are water-soluble properties of the high permeability of the cell membrane in it, the possibility that the blocking of electron transfer to the incomplete oxygen species would be act more effectively is suggested [47,48]. This is supported the theoretical background in the point that the propolis used in this study is pure water extract from propolis.

\section{CONCLUSION}

In this study, the authors have intended to investigate the effects that the exercise training and the intake of the water extract from propolis have on the activity of antioxidant enzymes. For this purpose, the experimental animals (SD rats) used in this experiment were applied to the experimental environment for 6 weeks. As a result, the following conclusions were obtained:

1. The concentration of the glucose and insulin in blood of the CON + Ex group and PA + Ex group which are the exercise parallel group were significantly decreased in comparison with the CON group which is a control group, whereas it was confirmed that in the case of the concentration of glycogen in the skeletal muscle and liver tissue, the exercise parallel groups showed significantly high value in 
comparison with CON group.

2. In the case of the activity of the antioxidant enzyme in the skeletal muscle and the liver tissue, the activities of SOD, GPX and CAT in the gastrocnemius muscle tissue of $\mathrm{PA}+\mathrm{Ex}$ group showed significantly high value in comparison with other experimental groups. In addition, the SOD activity in the liver tissue showed that only PA + Ex group was significantly increased, whereas GDX activity showed significantly higher value in $\mathrm{CON}+$ Ex group and PA group than CON group. However, the activity of CAT in the liver tissue showed that there is no difference between the experimental groups.

3. As a result that measured the concentration of MDA in order to evaluate the damage level of the tissue by oxygen free radicals, the difference between the groups in the liver tissue was not shown, while it was shown that only PA+ Ex group in the skeletal muscle tissue was significantly decreased in comparison with other experimental groups.

Taken together the above findings, it is considered that the combination treatment of the exercise training and the water extract from propolis can not only increase the use of glycogen of the skeletal muscle and liver tissue, but also it can give the effect to suppress the activity of the antioxidant enzyme in the body, and in the future, the possibility as the exercise supplements and the antioxidant of the water-soluble propolis are expected.

\section{ACKNOWLEDGEMENTS}

This research was supported by Kyungpook National University Research Fund, 2012.

\section{REFERENCES}

[1] Kim JK, Roh SK. The effect of coenzyme Q10 supplementation on oxidative stress index and antioxidant capacity in the elderly. The Journal of Exercise Nutrition and Biochemistry. 2009;13:29-35.

[2] Castrogiovanni P, Imbesi R. Oxidative stress and skeletal muscle in exercise. Italian journal of anatomy and embryology. 2012;117:107-117.

[3] Xu J, Li Y. Effects of salidroside on exhaustive exerciseinduced oxidative stress in rats. Molecular medicine reports. 2012;6:1195-1198.

[4] Cho HC, Kim JK, Han JH, Kim JP, Ahn CS, Hong Y. The effect of propolis intake duration and concentration on free radical scavenging activity, peroxide value and fatigue variables induced by exercise. The Journal of Exercise Nutrition and Biochemistry. 2006; 10:27-35.

[5] Yin H, Xu L, Porter NA. Free radical lipid peroxidation: mechanisms and analysis. Chemical reviews. 2011. 12;111:5944-5972.

[6] Yang YK. The influence of simultaneous administration of selenium and vitamin $\mathrm{E}$ on antioxidant enzyme activity and lipid peroxidation. The Journal of Exercise Nutrition and Biochemistry. 2008;12:157-162.

[7] Kim JT, Lim IS. The effect of endurance training and rooibos-tea treatment during 12 weeks on the oxidative DNA damage, lipid peroxidation and antioxidant enzymes. The Journal of Exercise Nutrition and Biochemistry. 2010;13:141-145.

[8] Burdock GA. Review of the biological properties and toxicity of bee propolis (propolis). Food Chem Toxicol. 1998;36:347-63.

[9] Castaldo S, Capasso F. Propolis, an old remedy used in modern medicine. Fitoterapia. 2002;73:S1-6.

[10] Miorin PL, Levy Junior NC, Custodio AR, Bretz WA, Marcucci MC. Antibacterial activity of honey and propolis from Apis mellifera and Tetragonisca angustula against Staphylococcus aureus. Journal of applied microbiology. 2003;95:913-920.

[11] Hausen BM, Wollenweber E, Senff H, Post B. Propolis allergy. (II). The sensitizing properties of 1,1-dimethylallyl caffeic acid ester. Contact Dermatitis. 1987;17:171-177.

[12] Ahlin M, Dingizian V, Svenssson A. High frequency of contact allergy caused by alternative medicine substances. Tea tree oil tops the list. Lakartidningen. 2011;108: 1487-1490.

[13] Sforcin JM, Bankova V. Propolis: is there a potential for the development of new drugs? Journal of ethnopharmacology. 2011;133:253-260.

[14] Cho HC, Han JH, Kim JK, Hong Y. The effect of propolis(WEP) and vitamin $\mathrm{E}, \mathrm{C}$ intake on fatigue variable, scavenging of free radical and reducing of peroxide induced by exercise. The Korean Journal of Physical Education. 2006;45:687-697.

[15] Nakamura T, Ohta Y, Ohashi K, Ikeno K, Watanabe R, Tokunaga K, Harada N. Protective effect of Brazilian propolis against hepatic oxidative damage in rats with water-immersion restraint stress. Phytotherapy research. 2012;26:1482-1489.

[16] Nakamura T, Ohta Y, Ohashi K, Ikeno K, Watanabe R, Tokunaga K, Harada N. Protective Effect of Brazilian Propolis against Liver Damage with Cholestasis in Rats Treated with a-Naphthylisothiocyanate. Evidence-based complementary and alternative medicine. 2013;2013: 
302720.

[17] Dudley GA, Abraham WM, Terjung RL. (1982). Influence of exercise intensity and duration on biochemical adaptations in skeletal muscle. Journal of applied physiology. $53,844-850$.

[18] Martin JP Jr, Dailey M, Sugarman E. Negative and positive assays of superoxide dismutase based on hematoxylin autoxidation. Archives of biochemistry and biophysics. 1987;255:329-336.

[19] Lowry OH, Rosebrough NJ, Farr AL, Randll RJ. Protein measurement with the Folin phenol reagent. The Journal of biological chemistry. 1951;193:265-275.

[20] Lo S, Russell JC, Taylor AW. Determination of glycogen in small tissue samples. Journal of applied physiology. 1970;28:234-236.

[21] Yin H, Zhu M. Free radical oxidation of cardiolipin: chemical mechanisms, detection and implication in apoptosis, mitochondrial dysfunction and human diseases. Free radical research. 2012;46:959-974.

[22] Nam TG. Lipid peroxidation and its toxicological implications. Toxicological research. 2011;27:1-6.

[23] Shupik MA, Vanin AF, Alessenko AV. Interaction of the nitric oxide signaling system with the sphingomyelin cycle and peroxidation on transmission of toxic signal of tumor necrosis factor- $a$ in ischemia-reperfusion. Biochemistry. 2011;76:1197-1209.

[24] Roberts CK, Hevener AL, Barnard RJ. Metabolic syndrome and insulin resistance: underlying causes and modification by exercise training. Comprehensive Physiology. 2013;3:1-58.

[25] Turcotte LP, Fisher JS. Skeletal muscle insulin resistance: roles of fatty acid metabolism and exercise. Phytotherapy research. 2008;88:1279-1296.

[26] Borghouts LB, Keizer HA. Exercise and insulin sensitivity: a review. International journal of sports medicine. 2000;21:1-12.

[27] Aoi W, Hosogi S, Niisato N, Yokoyama N, Hayata H, Miyazaki H, Kusuzaki K, Fukuda T, Fukui M, Nakamura $\mathrm{N}$, Marunaka Y. Improvement of insulin resistance, blood pressure and interstitial $\mathrm{pH}$ in early developmental stage of insulin resistance in OLETF rats by intake of propolis extracts. Biochemical and biophysical research communications. 2013;432:650-653.

[28] Ueda M, Hayashibara K, Ashida H. Biofactors. Propolis extract promotes translocation of glucose transporter 4 and glucose uptake through both PI3K- and AMPKdependent pathways in skeletal muscle. BioFactors. 2013; 39:457-466.

[29] Li Y, Chen M, Xuan H, Hu F. Effects of encapsulated propolis on blood glycemic control, lipid metabolism, and insulin resistance in type 2 diabetes mellitus rats. Evidence-based complementary and alternative medicine. 2012;2012:981896.

[30] Armstrong RB, Phelps RO. Muscle fiber type composition of the rat hindlimb. The American journal of anatomy. 1984;171:259-272.

[31] Bonen A, Tan MH, Watson-Wright WM. Effects of exercise on insulin binding and glucose metabolism in muscle. Canadian journal of physiology and pharmacology. 1984; 62:1500-1504.

[32] Galbo H, Holst JJ, Christensen NJ. The effect of different diets and of insulin on the hormonal response to prolonged exercise. Acta physiologica Scandinavica. 1979;107: 19-32.

[33] Kwon TD, Ryu, SP, Jan EC, Lee SC. Effects of green tea polyphenol ingestion on blood lipids, MDA and SOD in rats. The Journal of Exercise Nutrition and Biochemistry. 2002;6:85-88.

[34] Ji LL, Gomez-Cabrera MC, Vina J. Role of free radicals and antioxidant signaling in skeletal muscle health and pathology. Infectious disorders drug targets. 2009;9: 428-444.

[35] Peternelj TT, Coombes JS. Antioxidant supplementation during exercise training: beneficial or detrimental? International journal of sports medicine. 2011;41:1043-1369.

[36] Goldfarb AH, McIntosh MK, Boyer BT, Fatouros J. Vitamin $\mathrm{E}$ effects on indexes of lipid peroxidation in muscle from DHEA-treated and exercised rats. Journal of applied physiology. 1994;76(4):1630-1635.

[37] Ho E, Karimi Galougahi K, Liu CC, Bhindi R, Figtree GA. Biological markers of oxidative stress: Applications to cardiovascular research and practice. Redox biology. 2013;1:483-491.

[38] Michel F, Bonnefont-Rousselot D, Mas E, Drai J, Therond P. Biomarkers of lipid peroxidation: analytical aspects. Annales de biologie clinique. 2008;66:605-620.

[39] Holloszy JO. Adaptation of skeletal muscle to endurance exercise. Medicine and science in sports. 1975;7:155164.

[40] Yan Z, Lira VA, Greene NP. Exercise training-induced regulation of mitochondrial quality. Exercise and sport sciences reviews. 2012;40:159-164

[41] Gomes EC, Silva AN, de Oliveira MR. Oxidants, antioxidants, and the beneficial roles of exercise-induced production of reactive species. Oxidative medicine and cellular longevity. 2012;2012:756132.

[42] Koyama H, Nojiri H, Kawakami S, Sunagawa T, Shirasawa T, Shimizu T. Antioxidants improve the 
phenotypes of dilated cardiomyopathy and muscle fatigue in mitochondrial superoxide dismutase-deficient mice. Molecules. 2013;18(2):1383-1393.

[43] Ji LL. Modulation of skeletal muscle antioxidant defense by exercise: Role of redox signaling. Free radical biology \& medicine. 2008;44:142-152.

[44] Kimoto T, Koya S, Hino K, Yamamoto Y, Nomura Y, Micallef MJ, Hanaya T, Arai S, Ikeda M, Kurimoto M. Renal carcinogenesis induced by ferric nitrilotriacetate in mice, and protection from it by Brazilian propolis and artepillin C. Pathology international. 2000;50:679-689.

[45] Banskota AH, Nagaoka T, Sumioka LY, Tezuka Y, Awale S, Midorikawa K, Matsushige K, Kadota S. Antiproliferative activity of the Netherlands propolis and its active principles in cancer cell lines. Journal of ethnopharmacology. 2002;80:67-73.

[46] Burdock GA. Review of the biological properties and toxicity of bee propolis (propolis). Food and chemical toxicology. 1998;36:347-363.

[47] Song YS, Park EH, Hur GM, Ryu YS, Lee YS, Lee JY, Kim YM, Jin C. Caffeic acid phenethyl ester inhibits nitric oxide synthase gene expression and enzyme activity. Cancer letters. 2002 Jan 10;175(1):53-61.

[48] Ilhan A, Akyol O, Gurel A, Armutcu F, Iraz M, Oztas E. Protective effects of caffeic acid phenethyl ester against experimental allergic encephalomyelitis-induced oxidative stress in rats. Free radical biology and medicine. 2004;37(3):386-394. 